\title{
A Subcutaneous Juvenile Xanthogranuloma in a 4-Year-Old Girl Who Presented with a Lower Eyelid Mass
}

\author{
Amjad A. Saifaldein ${ }^{a} \quad$ Faeeqah H. Almahmoudi ${ }^{b}$ Rafaa I. Babgi ${ }^{b}$ \\ Alaa A. Alsammahi ${ }^{\mathrm{c}}$ \\ aDepartment of Ophthalmology, KAMC - Ministry of Health, Jeddah, Kingdom of Saudi \\ Arabia; ' Department of Ophthalmology, King Fahad Armed Forces Hospital, \\ Jeddah, Kingdom of Saudi Arabia; 'King Abdulaziz University Hospital, Jeddah, Kingdom \\ of Saudi Arabia
}

\section{Keywords}

Infant · Juvenile xanthogranuloma $\cdot$ Eyelid

\section{Abstract}

Juvenile xanthogranuloma (JXG) is a relatively uncommon, benign, histiocytic proliferative cutaneous disorder that typically affects children, with the head and neck being the most common sites. The present case report describes an isolated subcutaneous JXG in a 4-year-old girl who presented with a circumscribed oval mass located in the lower eyelid of the right eye. This lesion was histologically diagnosed as JXG after a surgical resection of the mass.

\section{Introduction}

Although an uncommon condition, juvenile xanthogranuloma (JXG) is the most common form of non-Langerhans cell histiocytosis [1]. The first reported case of JXG was reported in 1905 [2], which was generally described as a benign, self-limited histiocytic disorder of the 
skin [3]. The incidence is unknown but has been reported to represent $0.5 \%$ of all paediatric tumours [4]. JXG may present at birth (5-17\% of cases) or in the first year of life (40-70\% of cases). During infancy, male predominance can be seen in the ratio of 1.5:1, with a tendency of spontaneous regression [5]. Up to $80 \%$ of JXG cases can present as a solitary lesion, with fewer cases presenting as multiple well-demarcated lesions [3]. Although the head, neck, and trunk are the most common sites for JXG, it can appear anywhere on the body, including the groin, scrotum, penis, clitoris, toenail, palm soles, and lip [6-8]. However, it may also occur in the bone, genitourinary tract, tympanic membrane, spinal column, brain cortex, bone marrow, lung, and liver [9-15]. Extracutaneous involvement is usually restricted to the eye area. Ocular involvement of JXG includes the orbit, eyelid, conjunctiva, limbus, uvea, retina, and optic disc [16-23]. Although mainly a cutaneous lesion, some rare cases have been reported as pure subcutaneous lesions. However, very few cases have been reported to involve the eyelid [9, 24-27].

We describe a case of an isolated subcutaneous JXG located in the lower eyelid without any additional cutaneous or systemic nodules in a 4-year-old girl.

\section{Case Report}

A 4-year-old girl presented to the ophthalmology outpatient clinic with history of painless right lower eyelid mass for 3 weeks. There was no history of bleeding or discharge from the surface of the lesion and no history of fever or trauma. The patient was not on any topical treatment or systemic medication.

She had a known case of lactose intolerance. Additionally, she had a previous history of abdominal distention at the age of 6 months and a history of poor appetite. The patient had no family history of similar illness. The patient's mother had a normal pregnancy and normal labour.

On examination, visual acuity without correction was 20/20 in both eyes (OU). Pupils were round, regular, and reactive to light with no afferent pupillary defect. Orthoptic evaluation showed orthophoria with full ocular motility OU. Her refraction was not significant OU.

Results of bilateral anterior and posterior segment examinations were within the normal range. The right lower eyelid mass was $1 \times 1 \mathrm{~cm}$ in size, firm, not tender, mobile, and well circumscribed. The skin above the lesion was red in colour (Fig. 1). There was a chalazion-like lesion on the left lower eyelid margin. Laboratory investigations including a complete blood count, liver function test, and renal function test were negative.

Magnetic resonance imaging (MRI) of the orbit showed an oval-shaped soft tissue lesion of the right lower eyelid which measured $0.6 \times 0.6 \times 0.7 \mathrm{~cm}$, with low signal on T1 and high intensity on T2. The lesion was confined to the subcutaneous tissue, not exerting any mass effect on adjacent structures and not arising from the bone. The globe, extra-ocular muscle, optic nerve, and retrobulbar fat were normal with no evidence of intra-orbital mass (Fig. 2). The patient was referred to a paediatrician for general investigation, including skeletal X-ray and abdominal ultrasound, which showed normal bones and visceral organs, respectively.

The patient had an excisional biopsy of the right lower eyelid mass (Fig. 3) and the specimen was sent for histopathology. Histopathology of the right eyelid mass showed multiple fragments of fibrovascular and granulation-like tissue, heavily infiltrated by inflammatory cells. Histopathology also revealed a non-caseating granuloma and collection of foamy histiocytes and rare Touton-like cells (Fig. 4). The specimen was negative for atypia and signs of malignancy, as well as being negative for CD1 and S100. According to these results, the patient 
was diagnosed with JXG. Histopathology of the left eyelid mass lesion showed a nonspecific chronic inflammatory response, suggestive of chalazion.

\section{Discussion}

JXG is a rare, benign lesion which is usually confined to the skin [25]. Ocular JXG may occur without concomitant skin involvement, with $92 \%$ of patients being younger than 2 years of age [28]. The ocular tissues affected by JXG include the iris (68\%), conjunctiva (19\%), eyelid (6\%), choroid (6\%), and orbit (3\%) [17]. Eye involvement is usually, but not always, unilateral and commonly presents with an asymptomatic iris tumour, a red eye with signs of uveitis, unilateral glaucoma, spontaneous hyphema, or heterochromia iridis [6]. Eyelid involvement by JXG is an uncommon presentation [21] and has only been reported in a small number of cases, with only 2 known cases involving the eyelid [13, 25, 29]. One such case was a congenital subcutaneous eyelid JXG with orbital involvement which was treated with an intralesional steroid [26]. The other case was reported in a 10-month-old infant, which resulted in visually significant astigmatic amblyopia [27].

We describe a case of solitary subcutaneous JXG involving the lower eyelid, without any other cutaneous or systemic lesions and non-significant refraction. JXG can be differentiated from xanthoma by the distribution of the lesion and absence of lipid abnormalities. Other differential diagnoses include molluscum contagiosum (pearly, dome-shaped papule with central umbilication), haemangioma, and neurofibroma (firm lesion with associated cafe-au-lait spots) [28].

The diagnosis of JXG is mainly based on characteristic clinical features and confirmed by histopathology. Histopathology of JXG is characterised by Touton giant cells which are seen in $85 \%$ of JXG cases. S-100 protein immunoreactivity, a marker for the diagnosis of Langerhans cell histiocytosis, is typically absent [30].

The lesion is sometimes associated with neurofibromatosis type 1 , juvenile chronic myelogenous leukaemia, Niemann-Pick disease, diabetes insipidus, lytic bony lesions, and urticaria pigmentosa $[3,6,30]$.

JXG is a self-limiting disease that often spontaneously regresses $[8,30]$. Lesions may resolve completely or may leave a residual atrophic or hyperpigmented scar. Conservative management of these lesions has been advocated [31]. Despite the likelihood of spontaneous regression, excision of the lesion(s) is often decided for aesthetic or diagnostic reasons, as was done in our case. Excision of the lesion is an adequate treatment and recurrence is uncommon, although it has been reported [32].

\section{Conclusion}

Juvenile xanthogranuloma is typically a benign and self-limiting disease, and treatment may be necessary to prevent amblyopia if the eyelid is involved. Early multidisciplinary evaluation for systemic lesions and associated malignant conditions should be considered.

\section{Statement of Ethics}

The authors have no ethical conflicts to disclose. 


\section{Case Reports in Ophthalmology}

Saifaldein et al.: Subcutaneous JXG in a 4-Year-Old Girl

\section{Disclosure Statement}

The authors report no conflicts of interest.

\section{References}

1 Weitzman S, Whitlock J. Uncommon histiocytic disorder: the non-Langerhans cell histiocytoses. In: Histiocytic Disorders of Children and Adults. Cambridge: Cambridge University Press; 2005. p. 293-320. Available from: https://doi.org/10.1017/CB09780511545252.016.

2 Adamson H. Society intelligence: the Dermatological Society of London. A case of congenital xanthoma multiplex. Br J Dermatol. 1905;17:222.

3 Sangüeza OP, Salmon JK, White CR Jr, Beckstead JH. Juvenile xanthogranuloma: a clinical, histopathologic and immunohistochemical study. J Cutan Pathol. 1995 Aug;22(4):327-35.

4 Janssen D, Harms D. Juvenile xanthogranuloma in childhood and adolescence: a clinicopathologic study of 129 patients from the kiel pediatric tumor registry. Am J Surg Pathol. 2005 Jan;29(1):21-8.

5 Palmer A, Bowling J. Dermoscopic appearance of juvenile xanthogranuloma. Dermatology. 2007;215(3):256-9.

6 Hernandez-Martin A, Baselga E, Drolet BA, Esterly NB. Juvenile xanthogranuloma. J Am Acad Dermatol. 1997 Mar;36(3 Pt 1):355-67.

7 Cypel TK, Zuker RM. Juvenile xanthogranuloma: case report and review of the literature. Can J Plast Surg. 2008;16(3):175-7.

8 Margulis A, Melin-Aldana H, Bauer BS. Juvenile xanthogranuloma invading the muscles in the head and neck: clinicopathological case report. Ann Plast Surg. 2003 Apr;50(4):425-8.

9 Chu MW, Werner A, Moody-Antonio SA. Juvenile xanthogranuloma of the tympanic membrane: a case report. Ear Nose Throat J. 2012 Sep;91(9):364-8.

10 Cao D, Ma J, Yang X, Xiao J. Solitary juvenile xanthogranuloma in the upper cervical spine: case report and review of the literatures. Eur Spine J. 2008 Sep;17 Suppl 2:S318-23.

11 Ernemann U, Skalej M, Hermisson M, Platten M, Jaffe R, Voigt K. Primary cerebral non-Langerhans cell histiocytosis: MRI and differential diagnosis. Neuroradiology. 2002 Sep;44(9):759-63.

12 Neveling U, Kahn LB, Valderrama E, Poustchi-Amin M, Uckan D, Shende A. Deep juvenile xanthogranuloma: an unusual presentation. Pediatr Pathol Lab Med. 1997 May-Jun;17(3):503-11.

13 Yeh BM, Nobrega KT, Reddy GP, Qayyum A. Juvenile xanthogranuloma of the heart and liver: MRI, sonographic, and CT appearance. AJR Am J Roentgenol. 2007 Oct;189(4):W202-4.

14 Suson K, Mathews R, Goldstein JD, Dehner LP. Juvenile xanthogranuloma presenting as a testicular mass in infancy: a clinical and pathologic study of three cases. Pediatr Dev Pathol. 2010 Jan-Feb;13(1):39-45.

15 Yamada K, Yasui M, Sawada A, Inoue M, Nakayama M, Kawa K. Severe persistent bone marrow failure following therapy with 2-chlorodeoxyadenosine for relapsing juvenile xanthogranuloma of the brain. Pediatr Blood Cancer. 2012 Feb;58(2):300-2.

16 Chaudhry IA, Al-jishi Z, Shamsi FA, Riley F. Juvenile xanthogranuloma of the corneoscleral limbus: case report and review of the literature. Surv Ophthalmol. 2004 Nov-Dec;49(6):608-14.

17 Samara WA, Khoo CT, Say EA, Saktanasate J, Eagle RC Jr, Shields JA, et al. Juvenile xanthogranuloma involving the eye and ocular adnexa: tumor control, visual outcomes, and globe salvage in 30 patients. Ophthalmology. 2015 Oct;122(10):2130-8.

18 DeBarge LR, Chan CC, Greenberg SC, McLean IW, Yannuzzi LA, Nussenblatt RB. Chorioretinal, iris, and ciliary body infiltration by juvenile xanthogranuloma masquerading as uveitis. Surv Ophthalmol. 1994 JulAug;39(1):65-71.

19 Wertz FD, Zimmerman LE, McKeown CA, Croxatto JO, Whitmore PV, LaPiana FG. Juvenile xanthogranuloma of the optic nerve, disc, retina, and choroid. Ophthalmology. 1982 Dec;89(12):1331-5.

20 Hildebrand GD, Timms C, Thompson DA, Atherton DJ, Malone M, Levitt G, et al. Juvenile xanthogranuloma with presumed involvement of the optic disc and retina. Arch Ophthalmol. 2004 Oct;122(10):1551-5.

21 Hayashi N, Komatsu T, Komatsu T, Hiroi M, Ueno H. Juvenile xanthogranuloma presenting with unilateral prominent nodule of the eyelid: report of a case and clinicopathological findings. Jpn J Ophthalmol. 2004 Sep-Oct;48(5):435-9.

22 Johnson TE, Alabiad C, Wei L, Davis JA. Extensive juvenile xanthogranuloma involving the orbit, sinuses, brain, and subtemporal fossa in a newborn. Ophthal Plast Reconstr Surg. 2010 Mar-Apr;26(2):133-4.

23 Olmo N, Barrio-Barrio J, Moreno-Montañés J, Panizo A. Conjunctival juvenile xanthogranuloma in a preschool child. Ocul Immunol Inflamm. 2013 Oct;21(5):403-4.

24 Sánchez Yus E, Requena L, Villegas C, Valle P. Subcutaneous juvenile xanthogranuloma. J Cutan Pathol. 1995 Oct;22(5):460-5. 


\section{Case Reports in Ophthalmology}

\begin{tabular}{l|l}
\hline Case Rep Ophthalmol 2019;10:153-159 \\
\hline DOI: 10.1159/000500224 & $\begin{array}{l}\text { @ 2019 The Author(s). Published by S. Karger AG, Basel } \\
\text { www.karger.com/cop }\end{array}$ \\
\hline
\end{tabular}

Saifaldein et al.: Subcutaneous JXG in a 4-Year-Old Girl

25 Guthrie JA, Arthur RJ. Case report: juvenile xanthogranuloma with pulmonary, subcutaneous and hepatic involvement. Clin Radiol. 1994 Jul;49(7):498-500.

26 Kuruvilla R, Escaravage GK Jr, Finn AJ, Dutton JJ. Infiltrative subcutaneous juvenile xanthogranuloma of the eyelid in a neonate. Ophthal Plast Reconstr Surg. 2009 Jul-Aug;25(4):330-2.

27 Kaur H, Cameron JD, Mohney BG. Severe astigmatic amblyopia secondary to subcutaneous juvenile xanthogranuloma of the eyelid. J AAPOS. 2006 Jun;10(3):277-8.

28 Kesavan TM, Sreedevi PK. Juvenile xanthogranuloma. Indian Pediatr. 2005 Sep;42(9):950.

29 Janney CG, Hurt MA, Santa Cruz DJ. Deep juvenile xanthogranuloma. Subcutaneous and intramuscular forms. Am J Surg Pathol. 1991 Feb;15(2):150-9.

30 Dehner LP. Juvenile xanthogranulomas in the first two decades of life: a clinicopathologic study of 174 cases with cutaneous and extracutaneous manifestations. Am J Surg Pathol. 2003 May;27(5):579-93.

31 Hagmann C, El-Bahrawy M, Stamp G, Abel RM. Juvenile xanthogranuloma: a case report of a preterm baby. J Pediatr Surg. 2006 Mar;41(3):573-5.

32 Sonoda T, Hashimoto H, Enjoji M. Juvenile xanthogranuloma. Clinicopathologic analysis and immunohistochemical study of 57 patients. Cancer. 1985 Nov;56(9):2280-6.

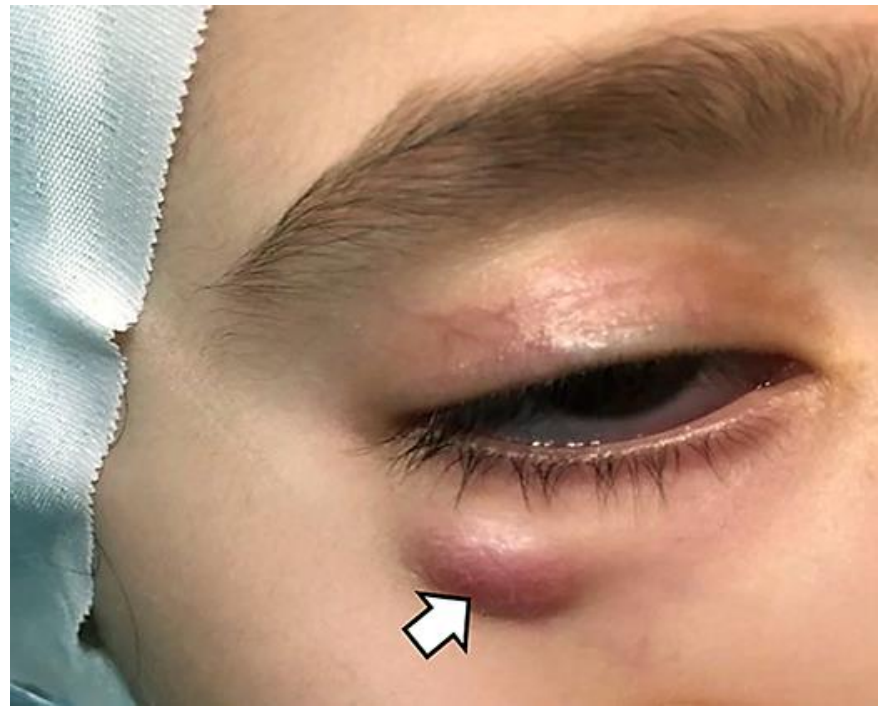

Fig. 1. Right subcutaneous lower eye lid mass 1 month after the initial presentation. 


\section{Case Reports in Ophthalmology}

\begin{tabular}{l|l}
\hline Case Rep Ophthalmol 2019;10:153-159 \\
\hline DOI: 10.1159/000500224 & $\begin{array}{l}\text { @ } 2019 \text { The Author(s). Published by S. Karger AG, Basel } \\
\text { www.karger.com/cop }\end{array}$ \\
\hline Saifaldein et al. Subcutaneous JXG in a 4-Year-Old Girl
\end{tabular}

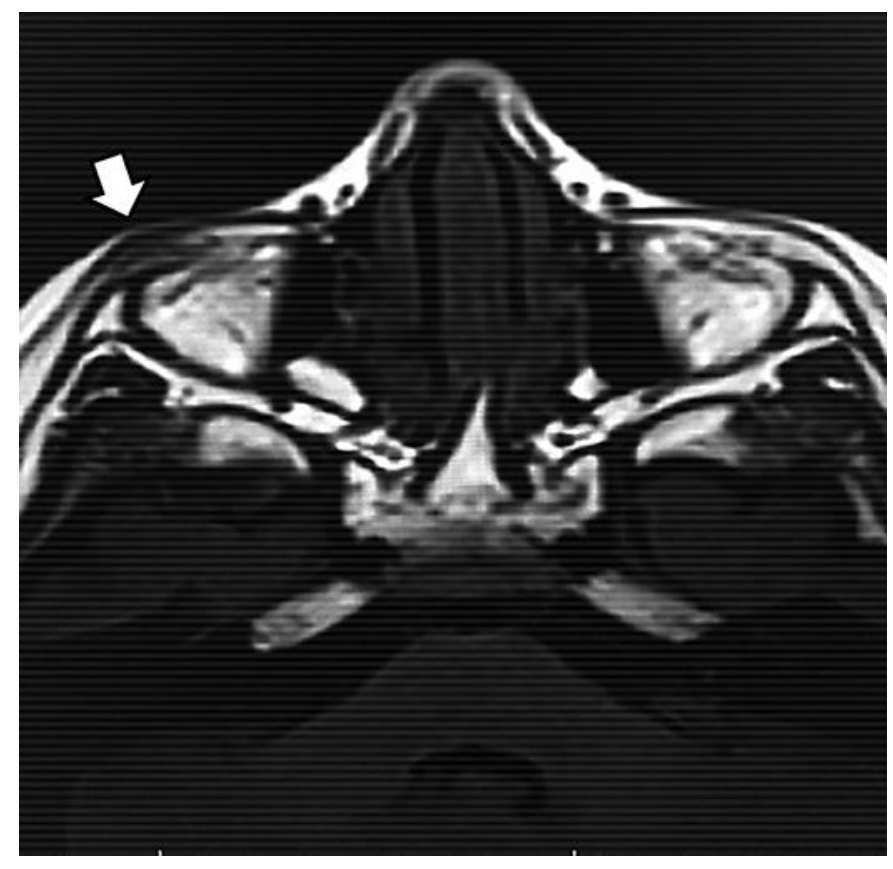

Fig. 2. MRI T1 axial plane, the arrow points to the mass - an oval-shaped soft tissue lesion of the lower eyelid of the right orbit, measuring $0.6 \times 0.6 \times 0.7 \mathrm{~cm}$ with low signal.

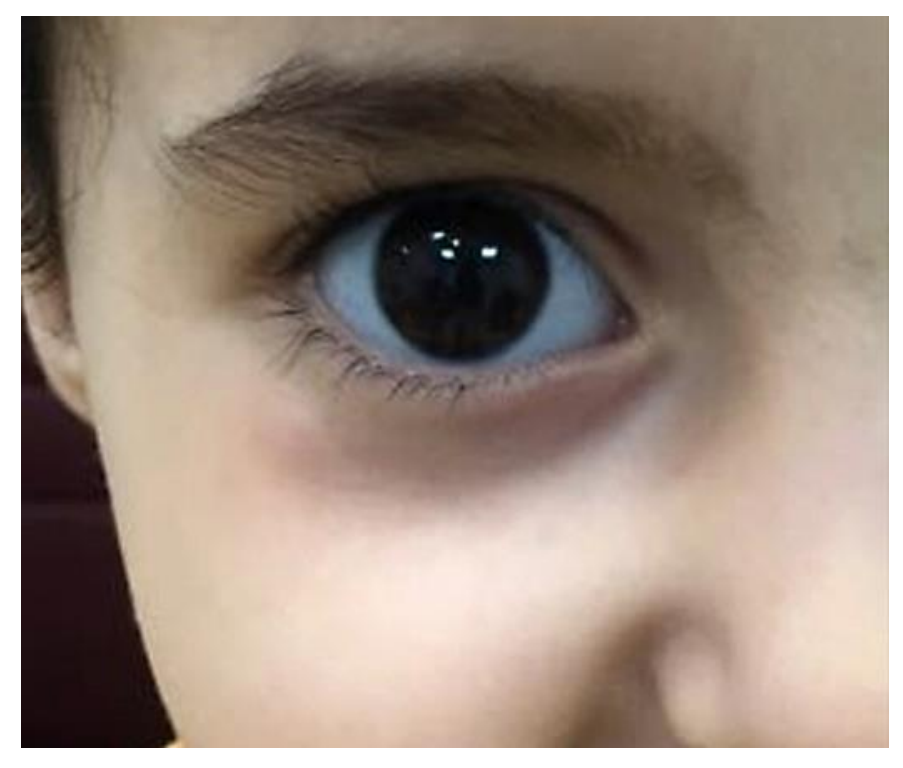

Fig. 3. Postoperative week 6. 

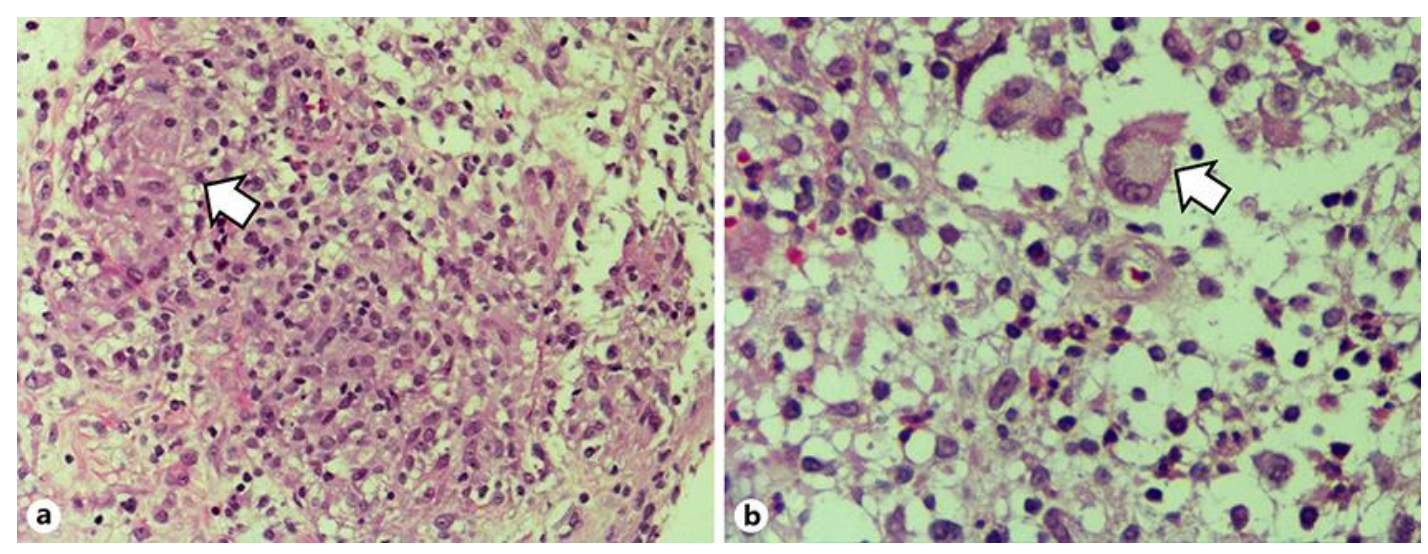

Fig. 4. Right eye. a Non-caseating granuloma. b Touton-like giant cells. 